\title{
5 Conducting EMI with students of diversified backgrounds
}

\author{
The case of business management
}

\author{
Hsiou-Wei William Lin and Anita Chunwen Lin
}

\section{Introduction}

Amidst the global phenomenon of English being used as the medium of instruction (EMI) in universities in non-English-speaking regions or countries, it has been found, both in Taiwan and abroad, that such a trend is particularly prevalent in several academic disciplines, including the fields of business and management (Dearden, 2014; Macaro et al., 2018; Pritasari et al., 2019; Wilkinson, 2011). The well-established status of English as the lingua franca across business and other professional areas renders it an obvious choice for the medium of instruction for universities that aim to internationalize their campuses. Also, as the degree of internationalization, in terms of the number of international students and staff, is an important indicator for business school rankings, EMI has been promoted to facilitate the recruitment of overseas faculty and students.

Stakeholders involved in designing and delivering EMI programs and courses in business and management are faced with issues already widely discussed in EMI-related research, such as students' lack of speaking skills required for participating in discussion tasks and the lack of student engagement in the classroom (e.g., Airey, 2011; Chang, 2010; Evans \& Morrison, 2011; Fenton-Smith et al., 2017; Flowerdew et al., 2000; Huang, 2009, 2012, 2014). In addition, subject teachers in these fields face the pressure of managing classes that often comprise students of diverse first languages, cultures, academic backgrounds, motivations for taking EMI classes, and registration statuses (e.g., degree vs. exchange). Moreover, in keeping with the practice of including case study research in their courses, EMI teachers are expected to lead case discussions in English, through which students have opportunities to analyze real-life business situations, gather information, identify problems and concerns that businesses encounter, propose strategies or solutions that can be adopted by these businesses, and finally, gain insight into complex business issues. All of these competencies are not only important to classroom performance but also indispensable for actual business communication and decisions. To encourage students to actively express their opinions and exchange viewpoints with one another during case study research, EMI 
instructors need to carefully devise various interactive tasks (e.g., teacher-led class discussions) and oversee the implementation of these tasks (Esteban \& Cañado, 2004; de Prat, 2020; Northcott, 2007). All of the above constitute challenges and concerns for EMI teachers in the business and management fields.

This chapter bases its observations on a top-tier national university in Taiwan that, during the past decade, has embarked on an initiative to implement EMI for content courses. The chapter will therefore provide a case study of the current status of the implementation of EMI in a specific Taiwanese context of the business management field. Then pedagogical practices and challenges specific to the discipline, such as the expectation that the subject teachers will manage case discussions with students of diverse backgrounds, will be described. Next, pedagogical guidelines for enhancing interactions both between teachers and students and among students will be suggested. The chapter will conclude by providing discussions and suggestions on the employment of these guidelines. It should also be pointed out that the purposes of the present chapter are not to investigate the possibility of promoting English learning itself through EMI in business management, the impact of English language proficiency on the delivery of EMI classes, or the language needs of these classes. Rather, the main focus of this chapter will be the ways instructors can conduct business subject classes in English while maintaining or even enhancing class interactions, a challenge often mentioned by EMI teachers and researchers.

\section{Implementing EMI in the business management field}

Similar to most other higher education institutions in Taiwan, the university reported on in this chapter has experienced significant growth in the number of EMI courses in recent years. The university's online course-search system shows that in the second (spring) semester of the 2018 academic year, over 900 EMI courses were offered on the campus. This number, which is six times the number of EMI courses offered a decade ago, reflects the institution's intent to fulfill goals outlined in the projects related to the development of higher education initiated by Taiwan's Ministry of Education (2001, 2011, 2013, 2016) and the university's own aspirations to improve its university ranking internationally. Currently, EMI courses account for $6 \%$ to $7 \%$ of the total course offerings, in line with the average proportion of EMI courses to total courses country-wide (Chung \& Lo, 2016).

The university comprises a wide range of fields of study in science, the arts, and humanities. Among them, the College of Management is known for its desire to expand the implementation of EMI. First, one of the college's core values is a commitment to equipping students with the English communicative skills required in academic and business domains. Therefore, EMI courses are considered as platforms for preparing local students with the necessary communication skills. Second, a sufficient supply of EMI courses is 
viewed as one of the prerequisites for sustaining continued collaboration on exchange programs with international partner business schools. For example, a 2016 report from the college explicitly stated that "an increasing number of EMI courses are being offered to respond to new contracts with international institutions on exchange programs and to meet the needs of incoming foreign students sent by these partner institutions." (College of Management of National Taiwan University, 2016). In fact, EMI courses offered by this college, like those offered by business colleges in other Taiwanese universities, are often popular among both business major and non-business major international students due to these courses' availability and variety in terms of the topics covered. Each semester, the College of Management hosts an average of 200 international students of more than 60 nationalities. To accommodate these students, it offers around 70 EMI courses as well as two Master of Business Administration (MBA) programs offered in English, more than the number of English taught courses offered by most other colleges in the same university. The phenomenon of the business management discipline offering more EMI courses than other disciplines do is consistent with what has been observed in other universities in Taiwan (Dearden, 2014).

The college has identified specific measures to promote the implementation of EMI. It encourages its in-service teachers to deliver courses using English by providing them with financial subsidies and human resources such as teaching assistants. In addition, since 2010, preparedness to conduct content courses in English has become an important criterion in the recruitment process for new faculty members. The newly-recruited teachers are expected to offer EMI courses for at least six years. Similar policies, either written into contracts or verbally agreed upon by both the hiring institutions and the new hires, have also been adopted by other business colleges in Taiwan. For instance, a recruitment announcement from a management-related department at one university specified that the new hires would have to offer at least three English or Chinese-English bilingual courses within three years of employment (National Taipei University of Technology, 2019). A similar announcement from the business management department at another university specified that the new hires would have to teach at least two credits in English per academic year (National Central University, 2019).

It should be noted that most of the college's subject teachers consider English the only, or at least the dominant, language for conducting lectures, activities, and assessment tasks in EMI courses. Such a practice may be attributed to the presence of international students, who usually make up more than half of the class. Another reason for the practice is the nature of the content of business courses, which is considered "internationally-oriented" (Macaro, 2018). In terms of language requirements for students from nonEnglish-speaking regions or countries, currently no English language proficiency test-score benchmarks have been set for admission to the EMI courses offered by the college. Nor do EMI instructors themselves feel it is legitimate to set any prerequisites for the enrollees regarding their English language 
proficiency. In contrast, applicants to the English-based MBA programs are required to submit English language scores for tests such as the TOEFL iBT or IELTS unless they are from English-speaking countries or have earned a graduation certificate from an English-speaking country.

In sum, EMI-related policies do exist, despite the lack of language requirements. There are also academic subject teachers working to facilitate the implementation of these policies. A sufficient number of academic courses are taught in English, and a sufficient number of students participate in these courses in this specific EMI setting.

\section{Issues and challenges of EMI in the business management field}

Policies on internationalization and faculty recruitment as well as the presence of international students are commonly deemed as promising factors for EMI implementation. Nevertheless, some hurdles and challenges remain. Those are explained below.

\section{Diverse student backgrounds}

Students enrolled in the courses offered by the aforementioned management college are diverse in terms of their first languages, nationalities, reasons for taking EMI classes, and academic backgrounds. Typically, overseas students account for half of the students taking the EMI classes. Some of them are pursuing degrees, but many of them are short-term students who need to participate in EMI classes to earn credits during their limited stays on campus. These exchange students, who are often not majoring in business management, are sometimes perceived by their EMI teachers as less committed to their studies. As these short-term students are generally more interested in exploring local cultures than in focusing on academic studies, they can be deemed by fellow local students as irresponsible team members when it comes to group assignments. As a result, EMI teachers in this college found that they faced the difficulty of dealing with mixed classes composed of local and international students who have very different attitudes, linguistic backgrounds, and academic backgrounds.

\section{Large class size}

It is not unusual for EMI instructors of business field courses to manage classes that are overcrowded. For instance, EMI business courses are very commonly selected by the college's international students, including those related to organizational behavior, human resources management, investment, finance, and marketing. The numbers of students in these lecture or discussion courses range from 40 to 150 , far exceeding those in courses offered in other disciplines. Overcrowded classes present challenges for teachers, for the time devoted to interacting with and providing feedback to each student 
is reduced. To find ways to better engage with students in the learning process, teachers often need to implement a variety of interactive activities (e.g., inviting ideas from students in Q\&A sessions), which require additional planning and management.

\section{Inclusion of business cases}

The case study method, a pedagogy developed at Harvard Law School in 1870 (Carter \& Unklesbay, 1989; Merseth, 1991), is widely adopted by business schools around the world (Saks \& Haccoun, 2019). In accordance with international practices, case methods of learning are a core component of business education in Taiwan. Courses in the management college are often taught with at least one quarter of the class time dedicated to the study and discussion of business cases. Several issues with this approach arise in the EMI classroom. First, in the teaching aspect, the need for subject teachers to conduct case discussions with students of diverse backgrounds entails extra pressure in terms of effective and efficient course management and content delivery. For instance, in the case of the College of Management reported in this chapter, its EMI professors sometimes need to intervene within case study teams to solve conflicts arising from different learning attitudes and allegedly uneven divisions of group work. In the learning aspect, the impromptu nature of classroom case analyses may discourage students with lower English-speaking proficiency from actively taking part in the discussions or interactive tasks that require students to talk with one another or with their teachers. Furthermore, an important feature of the university's business management education is the inclusion of local and international cases, both of which are essential for developing a comprehensive understanding of business operations in global markets. However, cases discussing the operations of Taiwan-based enterprises are mostly written in Chinese. Due to constraints in time and resources, few EMI instructors are able to write cases in English on their own for Taiwan-based firms such as Largan Precision Company Limited, a company that manufactures electronic components, or $85^{\circ} \mathrm{C}$ Bakery Café, a coffee and bakery chain that operates shops in many parts of the world. Instead, EMI teachers predominantly adopt cases written in English from North American institutes such as Harvard University and the University of Western Ontario, as well as textbooks that discuss business operations in Europe or North America. Students in EMI classes consequently have limited access to these local cases and related analyses. These students therefore have few opportunities to study Taiwan's business environment.

Because of the inclusion of case studies, classroom interactions both among students and between teachers and students are an integral part of the business management course, regardless of the language of instruction. In the specific EMI context that is the focus of this chapter, teaching issues such as diverse student backgrounds and large class sizes can complicate how well students' engagement with learning activities and their interactions with 
teachers and fellow students may be facilitated and achieved. In EMI literature ensuring student engagement by increasing interaction has been a key concern (e.g., Chang, 2010; Chuang, 2015; Hsieh et al., 2007; Huang, 2014). These studies pointed out that the choice by EMI teachers of whether to incorporate interactive tasks (e.g., group discussions) in their classes is often related to factors such as discipline, course type, and class size. But they also showed that the employment of these tasks and students' active participation in the tasks have increasingly been considered essential elements of successful EMI practices. In the following sections, an overview of the perspectives from which previous research studies have viewed the purpose of interaction will be provided. Then the implementation of interactive activities in the EMI classroom in the context considered in this chapter will be described. Finally, some examples of approaches to and guidelines for conducting EMI courses will be offered with the aim of alleviating the challenges faced.

\section{Research on interaction in the EMI classroom}

Previous studies related to EMI in higher education have pointed out that subject teachers adopting English as the instructional language often encounter problems in capturing the attention of demotivated students. Interactive activities are therefore used as instructional approaches to promote student participation and to enhance the effectiveness of EMI teaching and learning (e.g., Chuang, 2015; Hsieh et al., 2007; Huang, 2014; Li \& Wu, 2018). When proposing suggestions on how future EMI classroom practices can be improved, these studies often included the introduction of interactive tasks or group activities that promote cooperation among students. For instance, teachers may require students to work in groups for their in-class assignments or term projects, for which they will be requested to discuss their thoughts with group members, listen to the members' ideas and concerns, resolve learning problems together, and present project results to their peers. Similar findings were also presented by a study (Lin, 2018) focusing on interaction in EMI classes in the same university that this chapter bases its observations on. In Lin's study, academic subject teachers in the disciplines of engineering and business management were interviewed, and these instructors considered fostering a positive classroom atmosphere a major challenge in their EMI classes. Although lack of interaction can also be an issue in Chinese-mediuminstruction classes, these EMI teachers saw creating a more interactive classroom as a way to better engage students in an environment of learning and teaching content knowledge via a foreign language.

For reasons mentioned previously, professional development programs and teaching guidelines designed for EMI teachers also encourage the use of interactive tasks such as activities that require students to work in pairs or groups. This approach is seen as a way to overcome the challenges mentioned previously (e.g., dealing with demotivated students, ensuring effective content delivery) and to create a learner-centered environment that allows students to 
develop higher-level competencies such as problem-solving and negotiating skills (Fenton-Smith et al., 2017; Horie, 2017; Tsou, 2017; Tsui, 2017).

Although incorporating interactive tasks is one of the recurrent recommendations made by EMI-related studies (e.g., Chuang, 2015; Hsieh et al., 2007; Huang, 2014; Li \& Wu, 2018), other research studies have indicated that interactive or discussion activities are rarely carried out in EMI classrooms, and that when they are employed, students have difficulties fully participating in them due to insufficient speaking skills or issues concerning learning styles (e.g., Chang, 2010; Chung \& Lo, 2016; FentonSmith et al. 2017; Flowerdew et al., 2000; Hu \& Lei, 2014; Huang, 2012; Joe \& Lee, 2013; Kim, 2017; Taguchi \& Naganuma, 2006; Tsou, 2017). Survey and interview studies have also found that teachers perceive promoting interaction or leading discussions in EMI classrooms to be a demanding and stressful task (e.g., Hu \& Lei, 2014; Li \& Wu, 2017). Once again, such a lack of interaction is viewed as one factor that undermines the effectiveness of EMI teaching and learning.

A review of the literature revealed that, despite much discussion in previous studies about the value of student participation and interaction in the EMI classroom, such studies were mostly focused on investigating stakeholder perceptions, reactions, or attitudes toward the role of interaction or the lack of it in various EMI contexts. Although some studies undertaken in the form of case studies have looked into actual examples of EMI course practices and offered practical guidelines for EMI curriculum design and teaching strategies (Chuang, 2015; Chung \& Lo, 2016; Hino, 2017; Joe \& Lee, 2013), relatively few studies have explored EMI practices from the perspectives of classroom interactive activities or the management of these activities.

\section{Approaches to and guidelines for promoting interaction in EMI courses}

Taking into account the research gap in the implementation and management of interactive activities in the EMI classroom, this section draws on the experiences of the first author, Professor Hsiou-Wei William Lin, and looks into actual EMI practices implemented in his classrooms. The section aims to offer practical suggestions and directions for conducting interactive activities and assigning collaborative tasks in the hope of improving the level of student engagement and the effectiveness of content delivery. The examples of interactive activities described below include conducting case study sessions, assigning team projects, and asking questions to engage students in the learning process.

Two points are worth noting here. First, the activities described below can be organized together as components of a main task and employed in EMI classes simultaneously. However, each activity can also be implemented individually based on course characteristics and objectives. Second, these activities, including Q\&A sessions and in- and out-of-class discussions, are carried 
out primarily in English. The role of the use of local students' first language in the EMI classroom will be discussed in the last section of this chapter.

\section{Conducting case study sessions}

The case study method is widely adopted by business schools around the world (Saks \& Haccoun, 2019). To conduct case study sessions, teachers should include in each case a company's background, specific problems that the company encounters, and dilemmas and constraints related to the company's business operation. On the basis of such information, students are expected to observe and analyze specific firm strategies and the environment or culture in which a business operates, to propose solutions for the company, and during the process of completing the study sessions, to enhance their problem-solving and critical thinking skills, all of which are competencies deemed essential in the business management discipline.

In the author's EMI courses, case study sessions usually comprise tasks related to reading case materials, listening to briefings, answering questions raised by the teacher, and talking about personal points of view. Students are also required to participate in various team meetings, discussions, and brainstorming sessions. The instructor hopes to not only increase students' understanding of complex business logic but also improve their teamwork and communication skills through different tasks and a variety of interactive activities.

EMI teachers who wish to employ case study sessions are recommended to consider the steps and procedures shown in Figure 5.1 and Table 5.2.

Occasionally, consider replacing the above task with intra-team discussion tasks. Always circulate among groups during these discussions, offering support to students as needed. Make sure to walk around and listen in on several groups. This is necessary, for students judge the importance of the task by observing whether teachers are involved in the discussion process. Also, the duration of each team discussion should be limited to 20 minutes at most, as students easily get distracted or lose focus when the discussion lasts too long. The discussion task can be followed by a 15-minute Q\&A session between the teacher and students.

If EMI teachers wish to assign one group per week to take charge of the designated case and offer its perspectives and thoughts on the set of five case questions to be discussed in the class, they are advised to adopt the methods presented in Figure 5.2 and Table 5.2.

\section{Assigning team projects}

In Taiwan, the frequent use of teamwork tasks has already been observed in management-related courses taught in Mandarin. In EMI classes, assigning team projects at the beginning of the semester can be particularly useful in that such projects allow students to explore and appreciate different perspectives 
(1) Assign students to groups of four or five people.

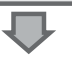

(2) Assign the same set of business cases to all of the groups (in the author's threecredit EMI classes, six to nine cases are assigned each semester). Specify the timeline for students in terms of when each case will be studied and discussed during the semester (for instance, a written report for the first case will be due in week two and its discussion session will take place in week three).

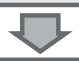

(3) For each case, prepare three to five case questions and provide a brief verbal summary of these questions in class when the case and reading materials are distributed. Sample case questions are provided in Table 5.1 below.

(4) Request that students read the distributed materials and submit a two-page written report as a group in response to the case questions. Group members are required to schedule team meetings in which they can share their viewpoints on the case with one another and develop their preliminary responses to the case questions.

(5) Lead in-class discussions by inviting students from different groups to respond to different sets of case questions. Each set is usually composed of five questions comprising pre-assigned questions and follow-up questions that are provided to students on the spot. Call on five students to respond to each question so that as many as 25 students can be involved in each discussion session. When a particularly intriguing point is raised by a student, lead other students to reflect, comment, or extend on that point (see "Asking questions to engage students in the learning process" in this section for more information on how teacher-student Q\&A can be conducted). The frequency of such discussion tasks can correspond to the number of cases assigned by the instructor. At least half an hour (out of the three hours that the author's courses meet per week) is allocated for the completion of each in-class discussion task.

Figure 5.1 Steps and procedures recommended for conducting case study sessions.

through teamwork and interaction. The "case study sessions" described above involve elaborate team efforts. For example, students are required to submit a written report as a group in response to the case questions, schedule team meetings outside of class, and participate in classroom discussions. However, 
Table 5.1 Sample case questions to be responded to in the 2-page written report

高譚市桌遊公司個案

The Gotham City Board Game Company Case

1. 為做好比較兩個專案的準備, Sean White 還需要哪些額外訊息? 他該向兩專案 主管問甚麼問題呢?

What additional information does Sean White need to complete his analyses and compare the two projects (Projects A and B)? What specific questions should he ask each of the project sponsors to get this information?

2. Sean White所面對兩個互斥專案中, 你認為較佳的是哪一案? 為什麼?

Comparing the two mutually exclusive projects under consideration by Sean White, which do you regard as more compelling? Why?

3. A方案的投資回收年數是多少?

How many years will it take for Project A to pay back the investment by the Gotham City Company?

(1) Schedule a meeting with the assigned group approximately one week before the discussion day to ensure that the group members fully understand the preassigned questions and are properly prepared before the discussion day.

(2) During the in-class discussion, randomly invite students from other groups to respond to the follow-up questions so that all students are aware that they also need to study the designated case beforehand even though they are not members of the assigned group.

Figure 5.2 Methods recommended for assigning case discussions to specific groups.

Table 5.2 Dos and don'ts for conducting case study sessions

Dos Don'ts

- Do request that students participate in team meetings and brainstorming sessions before in-class discussions.

- Do conduct in-class discussions by asking both pre-assigned questions and questions that are provided to students on the spot.

- Do encourage participation from the responding student as well as other students by posing follow-up questions to the responding student's answers.
- Don't allow the student who is designated to answer a specific question to delegate the task to another team member.

- Don't allow students to argue with one another for more than five minutes without the teacher's intervention.

- Don't yield the podium to the group assigned to host the discussion session for more than 15 minutes without the teacher's posing questions or making comments. 
depending on the course objectives, other types of team assignments may allow students in the EMI classroom more leeway in developing topics or conducting research. For instance, some teachers might ask students working together to create a logo for a company or to write a business plan for an enterprise, expecting that the students will be inspired by their teammates' creative ideas.

Previous studies (Johnson \& Johnson, 1999; Johnson et al., 1998) have discussed the elements that constitute a cooperative group in the classroom. It has been pointed out that without proper structuring or intervention from teachers, the intended cooperative learning is likely to be replaced by a traditional setting of group learning. In such an environment, assignments are structured in ways that students are predominately assessed or ranked as individuals instead of as members of a group, which results in a lack of a shared sense of responsibility and insufficient interaction among students.

In the EMI context discussed in this chapter, traditional learning groups have often led to student complaints. When team members lack consensus on the level of commitment that should be made to the group project, team discussions can be loose and inefficient. Students not as involved as their peers are seen as free-riders, and those who are hard-working feel taken advantage of. Also, it might be difficult for EMI teachers to stay informed of the contribution made to the group project by each group member, which can also be a source of dissatisfaction from the group members who are working the hardest in the team.

Listed in Figure 5.3 and Table 5.3 are a few measures taken by the author to implement team projects in a meaningful way and to create cooperation that can motivate students to achieve project goals as a group.

\section{Asking questions to engage students in the learning process}

Teachers asking questions that elicit solutions or opinions from their students is a common classroom practice in the field of business management. Preferably, at least two questions, one being a higher-order question that probes students' understanding of the course content, should be raised in each two or three hour session. This technique helps teachers clarify important or complicated concepts for students through interaction. It also encourages students to reflect on their understanding of the course content.

Questioning students can also be a valuable method in the EMI context. Using English as the medium of instruction and learning can sometimes be taxing for both teachers and students. EMI classes, especially lecture-based ones, easily become monologic throughout the entire class time. Interaction can be rare or limited to that between a few specific students and the teacher. Calling on students to participate in Q\&A sessions thus allows teachers and students to take a break from the instructor-dominated lecture format and creates opportunities for interaction and student participation. 
(1) Allow students to form their own groups at the beginning of the semester. Each group must include at least one local student and at least one international student.

(2) Request a meeting with a different team each week during office hours. Use this as a chance to monitor team progress and to discuss with team members their project in detail and their respective roles and responsibilities in the group. Depending on class size, each group can meet with the teacher once or twice per semester.

(3) Request that each group prepare their three most urgent questions for the teacher ahead of the team meeting.

(4) Specify that groups will need to submit a brief division-of-labor report at the end of the semester.

Figure 5.3 Steps and procedures recommended for implementing team projects.

Table 5.3 Dos and don'ts for assigning team projects

Dos Don'ts

- Do request a meeting with a different team each week during office hours.

- Do specify in the syllabus that groups will need to submit a brief divisionof-labor report at the end of the semester.

- Do assess or rank students' performances on the team project based primarily on their performances as members of a group instead of as independent individuals.
- Don't allow students to form groups that consist of only local students or international students.

- Don't ignore students' complaints about free-riders on their teams or depend on students entirely to resolve group conflicts all on their own.

- Don't allow a team presentation or discussion to become a one-person show.

More specifically, EMI teachers may adopt a cold-calling strategy and randomly appoint students to offer their opinions to prevent the familiar situation of the majority of students never raising their hands or responding. Such a strategy serves the purpose of stimulating student involvement and enhancing the quality of interaction in the classroom (Dallimore et al., 2013). 
Its effectiveness, nevertheless, often depends on how teachers implement the questioning task and how student responses are followed up by teachers or fellow students.

For cold-calling to function properly, EMI teachers are advised to consider the measures presented in Figure 5.4 and Table 5.4.

(1) Implement cold-calling halfway through the class as well as before the end of the class. Each Q\&A session can last around 10 to 15 minutes.

(2) To ensure that the first few students are willing to respond to the questions, choose in advance which students to cold-call. Identify role model students who are not necessarily the most fluent English speakers but are eager to share their thoughts. Bear in mind that cold-calling only those who speak fluent English may intimidate students with lower English proficiency.

(3) Avoid long and complicated questions. Instead, keep cold-calling questions succinct. Also, these questions should include higher-order questions that probe students' understanding of the course content. An open question such as "Why do you think increasing the current-year profit is more important than increasing the market share for this company?" can be asked.

(4) Restructure questions, use back-up questions, or provide support when students fail to provide appropriate or relevant answers. For example, EMI teachers may ask "Isn't increasing the market share also important for firms in this industry?" At the same time, they may draw on the blackboard a pie chart with a pie slice showing the company's sales volume in contrast with the overall market volume (the whole pie). Also, they may write next to the English term “market share” its Chinese translation, “市場占有率."

(5) Facilitate interaction and encourage further participation from the responding student or other students by posing follow-up questions. For instance, questions such as "Could you provide a few reasons to support your recommendations?" or "What may be the reasons why she makes a different decision?" invite students to provide explanations for their answers.

Figure 5.4 Steps and procedures recommended for implementing cold-calling strategy. 
Table 5.4 Dos and don'ts for asking questions to engage students in the learning process

\begin{tabular}{ll}
\hline Dos & Don'ts \\
\hline $\begin{array}{l}\text { Do implement cold-calling halfway } \\
\text { through the class as well as before the } \\
\text { end of the class. }\end{array}$ & $\begin{array}{l}\text { Don't ask long and complicated } \\
\text { questions during in-class discussion. }\end{array}$ \\
$\begin{array}{l}\text { Do restructure questions or use back- } \\
\text { up questions when students, especially } \\
\text { those with limited English proficiency, } \\
\text { fail to provide appropriate or relevant } \\
\text { answers. }\end{array}$ & $\begin{array}{l}\text { Don't limit the interaction to that } \\
\text { between a few specific students and } \\
\text { the teacher. }\end{array}$ \\
\hline
\end{tabular}

\section{Discussion}

As mentioned previously, ensuring student engagement by increasing interaction has become a shared concern for EMI teachers despite the unique challenges and issues of each EMI context. Interactive activities such as discussion tasks are considered by researchers and EMI teachers to be teaching techniques or strategies that promote class participation and enhance the effectiveness of EMI courses. Below are a few considerations and issues worth thinking about when employing the three approaches provided in the preceding section.

First of all, the above approaches are generally applicable to EMI courses at both the undergraduate and postgraduate levels. One reason is that the Master's-level programs in the fields of business and management are often focused on practical knowledge and skills rather than academically-oriented curricula. Bennis and O'Toole (2005) stated that some of the most difficult questions facing business managers may be broad as well as multifaceted and do not lend themselves to scientific experiments or validation. They provided examples of managerial questions such as: "What impact does a culture of celebrity have on leadership?", "How should a CEO be compensated?", "How should global operations be designed to be effective and equitable?", and "What purposes does a corporation have beyond the creation of shareholder value?" Another reason is that these Master's programs in general accept more students than do their counterparts in other disciplines. In the case of the university reported on in this chapter, each of its five full-time MBA programs operated by five different departments on average register 40 to 60 students each academic year. For the majority of these students, the MBA serves as a terminal degree. Most business graduate students do not plan to pursue a doctoral degree after graduation. For these reasons, the characteristics of Master's-level EMI courses in the colleges of management in principle resemble those of undergraduate ones. Nevertheless, it is advisable for teachers to consider the instructional objectives and learning goals 
of their EMI courses when determining their classroom practices because the implementation of EMI can be highly contextualized (Macaro et al., 2018).

Second, regardless of the type of interactive activities that EMI teachers adopt, it is suggested that the teachers communicate clearly to their students the goals and expected outcomes of the activities (Horie, 2017; Lin, 2018). Taking the assignment of team projects as an example, students should be informed at the start of the semester that task completion will require collaborative effort, such as holding team meetings before discussion sessions and gaining an understanding of the assigned business cases by responding to the guiding questions in written form. Students should also be made aware that all team members will need to take part in class discussions and be prepared to answer questions during the Q\&A sessions following the discussions. Making the course expectations clear to students enables the students to better engage with each step of the activities they undertake in the classroom.

Third, in the process of approaching activity goals, both monitoring and intervention from EMI teachers are required to provide students with guidance and to ensure that the assigned interactive or collaborative tasks indeed support the intended purposes (Hsieh et al., 2007; Tsou, 2017). Continuing the example of assigning team projects, teachers taking time out of their office hours to meet with each team at least once per semester is recommended so that any issues that might affect or disrupt teamwork can be detected and resolved in a timely manner. Conducting case study sessions is another example where monitoring and intervention are critical to the successful implementation of interactive activities (Esteban \& Cañado, 2004; de Prat, 2020; Northcott, 2007). In these sessions, not only do teachers initiate topics and frame the discussion around key issues, but they also need to manage the interaction process by intervening as necessary to make sure that all points of view and perspectives most relevant to the topics are raised and covered.

Next, although English is the dominant language and the activities are almost always conducted in that language in the EMI context discussed in this chapter, EMI teachers should acknowledge the importance of allowing some flexibility in adopting students' first languages in accordance with teaching and learning needs. Just as the choice by EMI teachers of whether to use interactive classroom activities should be based on course objectives, the choice of whether to incorporate first languages in EMI classes should be in line with instructional objectives and learning goals ( $\mathrm{Li} \& \mathrm{Wu}$, Chapter 7). For example, Mandarin Chinese is used in the first author's EMI classes to provide students with guiding questions or discussion prompts in both Chinese and English (see Table 5.1). Since these questions and prompts are meant to offer students direction in investigating the business cases assigned in class, having them available in both languages facilitates students' grasp of the questions and the discussion process. Another example is that, to ensure comprehension, the instructor responds to student questions or provides 
explanations in English while simultaneously writing on the blackboard the Chinese terms corresponding to the relevant English terms.

Lastly, inadequate support or resources for EMI instructors, such as the lack of professional development programs, has been identified in the literature as one of the main challenges facing EMI implementation (e.g., Coleman, 2006; Kim, 2017; Macaro, 2015; Wilkinson, 2012). In light of the instructional practices of the discipline of business management, this chapter would like to point to the scarcity of local business cases written in English as a problem specific to the English-based courses or programs in the business management field. As discussed earlier, case methods of learning are a core component of business education. In Taiwan, there are cases written by university professors discussing the operations of domestic firms. Yet these cases are mostly written in Chinese and therefore rendered unavailable for use in EMI courses. While EMI teachers have the option of using business cases produced by North American institutes, these cases are insufficient to help students understand the perspectives of Taiwanese or ethnically Chinese business managers. Chamorro-Premuzic and Sanger (2016) stated that although the core ingredients of business leadership are universal (e.g., good judgment, integrity, and people skills), the full recipe for successful leadership requires culture-specific condiments. Namely, the absence of local cases in EMI classes deprives both international and Taiwanese students of opportunities to gain insights into the operations of Taiwan- or Asia-based enterprises. Considering the increasing prevalence of EMI in the fields of business and management, the need for translation or production of local business cases is pressing. A comprehensive plan to accumulate such business cases is recommended for inclusion in the development of overall college-level EMI policies. Only then can sufficient resources be allocated to support the production of local cases written in English, which is beneficial in creating a more balanced and diverse learning agenda.

\section{Conclusion}

In the discipline of business management, the well-established status of English as the lingua franca across academic and business areas renders it an obvious choice for the medium of instruction for universities wishing to internationalize their business-related programs and recruit overseas students. As with the EMI courses offered by other areas of study, issues concerning classroom interaction and student engagement have remained a constant source of worry and frustration for both subject teachers and students. EMI teachers in the business management field might be facing challenges that are specific to their discipline, such as leading case studies in a heterogeneous classroom, but because of these circumstances, they also have the advantage of an enriched approach to conducting English-based courses, wherein the language is used by students as an international language across a range of interactive activities. With proper planning and preparation, academic subject teachers who 
are tasked with the responsibility of transmitting professional knowledge in English have the opportunity to enhance interaction and collaboration in their classrooms so that teachers can motivate students more effectively and students can engage with learning goals more actively.

\section{References}

Airey, J. (2011). Talking about teaching in English: Swedish university lecturers' experiences of changing teaching language. Ibérica, 22, 35-54.

Bennis, W. G., \& O'Toole, J. (2005). How business schools lost their way. Harvard Business Review, 83(5), 96-104.

Carter, K., \& Unklesbay, R. (1989). Cases in teaching and law. Journal of Curriculum Studies, 21, 527-536.

Chamorro-Premuzic, T., \& Sanger, M. (2016). What leadership looks like in different cultures. Harvard Business Review. Retrieved from www.hbr.org/2016/05/ what-leadership-looks-like-in-different-cultures

Chang, Y. Y. (2010). English-medium instruction for subject courses in tertiary education: Reactions from Taiwanese undergraduate students. Taiwan International ESP Journal, 2(1), 55-84.

Chuang, Y. T. (2015). An EMI pedagogy that facilitates students' learning. English Language Teaching, 8(12), 63-73.

Chung, C. L., \& Lo, M. L. (2016). Prospect and case study of English-medium instruction of transportation courses in Taiwanese universities. English Teaching \& Learning, 40(3), 81-121.

Coleman, J. A. (2006). English-medium teaching in European higher education. Language Teaching, 39(1), 1-14.

College of Management of National Taiwan University. (2016). A comprehensive plan for enhancing the academic quality of top universities. Retrieved from www.top100. ntu.edu.tw/outcomes/59/105.pdf [URL inactive]

Dallimore, E. J., Hertenstein, J. H., \& Platt, M. B. (2013). Impact of cold-calling on student voluntary participation. Journal of Management Education, 37(3), 305-341.

de Prat, J. M. (2020). Teaching through English: The case of International Commerce. In M. L. Carrió-Pastor, (Ed.), Internationalising learning in higher education: The challenges of English as a medium of instruction (pp. 179-200). London: Palgrave Macmillan.

Dearden, J. (2014). English as a medium of instruction - A growing global phenomenon. London, UK: British Council.

Esteban, A. A., \& Cañado, M. L. P. (2004). Making the case method work in teaching Business English: A case study. English for Specific Purposes, 23(2), 137-161.

Evans, S., \& Morrison, B. (2011). Meeting the challenges of English-medium higher education: The first-year experience in Hong Kong. English for Specific Purposes, 30(3), 198-208.

Fenton-Smith, B., Humphreys, P., \& Walkinshaw, I. (2017). English medium instruction in higher education in Asia-Pacific: From policy to pedagogy. Cham, Switzerland: Springer.

Fenton-Smith, B., Stillwell, C., \& Dupuy, R. (2017). Professional development for EMI: Exploring Taiwanese lecturers' needs. In B. Fenton-Smith, P. Humphreys, \& I. Walkinshaw (Eds.), English medium instruction in higher education in AsiaPacific: From policy to pedagogy (pp. 195-217). Cham, Switzerland: Springer. 
Flowerdew, J., Miller, L., \& Li, D. (2000). Chinese lecturers' perceptions, problems and strategies in lecturing in English to Chinese-speaking students. RELC Journal, 31(1), 116-138.

Hino, N. (2017). The significance of EMI for the learning of EIL in higher education: Four cases from Japan. In B. Fenton-Smith, P. Humphreys, \& I. Walkinshaw (Eds.), English medium instruction in higher education in Asia-Pacific: From policy to pedagogy (pp. 115-131). Cham, Switzerland: Springer.

Horie, M. (2017). Faculty training for non-native speakers of English at Japanese universities: Effective English-medium teaching for a culturally diversified student population. In A. Bradford \& H. Brown (Eds.), English-medium instruction in Japanese higher education: Policy, challenges and outcomes (pp. 207-221). Clevedon, UK: Multilingual Matters.

Hsieh, S. H., Kang, S. C., Li, W. J., Chang, K. I., \& Chen, R. C. (2007). 工程學科以英語授課之教學策略及有效性研究 [The effectiveness of Englishmedium instruction and pedagogical strategies in an engineering course]. Taipei, Taiwan: Department of Civil Engineering, National Taiwan University. Retrieved from www.ctld.ntu.edu.tw/rp/report/96_01.pdf

Hu, G., \& Lei, J. (2014). English-medium instruction in Chinese higher education: A case study. Higher Education, 67(5), 551-567. doi:10.1007/s10734-013-9661-5

Huang, Y. P. (2009). English-only instruction in post-secondary education in Taiwan: Voices from students. Hwa Kang Journal of English Language \& Literature, $15,145-157$.

Huang, Y. P. (2012). Design and implementation of English-medium courses in higher education in Taiwan: A qualitative case study. English Teaching \& Learning, 36(1), 1-51.

Huang, Y. P. (2014). Teaching content via English: A qualitative case study of Taiwanese university instructors' instruction. Foreign Language Studies, 20, 27-62.

Joe, Y., \& Lee, H. (2013). Does English-medium instruction benefit students in EFL contexts? A case study of medical students in Korea. The Asia-Pacific Education Researcher, 22(2), 201-207. doi:10.1007/s40299-012-0003-7

Johnson, D. W., \& Johnson, R. (1999). Making cooperative learning work. Theory into Practice, 38(2), 67-73.

Johnson, D. W., Johnson, R., \& Holubec, E. (1998). Cooperation in the classroom (7th ed.). Edina, MN: Interaction Book.

Kim, E. G. (2017). English-medium instruction in Korean higher education: Challenges and future directions. In B. Fenton-Smith, P. Humphreys, \& I. Walkinshaw (Eds.), English medium instruction in higher education in Asia-Pacific: From policy to pedagogy (pp. 53-69). Cham, Switzerland: Springer.

Li, M. Y., \& Wu, T. C. (2017). Creating an EMI program in international finance and business management. In W. L. Tsou \& S. M. Kao (Eds.), English as a medium of instruction in higher education: Implementations and classroom practices in Taiwan (pp. 95-114). Singapore: Springer.

Li, N., \& Wu, J. (2018). Exploring assessment for learning practices in the EMI classroom in the context of Taiwanese higher education. Language Education \& Assessment, 1(1), 28-44.

Lin, A. (2018). Interactive spoken English demand for English-medium instruction in tertiary education: A case study of Taiwan. Paper presented at the 5th Asian Association for Language Assessment (AALA) conference, Shanghai, China.

Macaro, E. (2015). English medium instruction: Time to start asking some difficult questions. Modern English Teacher, 24(2), 4-7. 
Macaro, E. (2018). English medium instruction. Oxford: Oxford University Press.

Macaro, E., Curle, S., Pun, J., An, J., \& Dearden, J. (2018). A systematic review of English medium instruction in higher education. Language Teaching, 51(1), 36-76.

Merseth, K. (1991). The early history of case-based instruction: Insights for teacher education today. Journal of Teacher Education, 42(4), 243-249.

Ministry of Education. (2001). White paper on higher education. Retrieved from www. ws.moe.edu.tw/001/Upload/3/RelFile/6315/6936/90.07\%E5\%A4\%A7\%E5\%AD \% B8\%E6\%95\%99\%E8\%82\%B2\%E6\%94\%BF\%E7\%AD $\% 96 \%$ E7\%99\%BD $\%$ E7\% $\%$ $\mathrm{A} \% \mathrm{AE} \% \mathrm{E} 6 \% 9 \mathrm{~B} \% \mathrm{~B} 8 . \mathrm{pdf}$ [URL inactive]

Ministry of Education. (2011). Study-in-Taiwan enhancement program. Retrieved from www.ws.ndc.gov.tw/Download.ashx?u=LzAwMS9hZG1pbmlzdHJhdG9yL zEwL1JlbEZpbGUvNTU2Ni81MjQxLzAwMTQ0NDUucGRm\&n=6auY562J 5pWZ6IKy6Ly45Ye6LeaTtOWkp\%2BaLm\%2BaUtuWig\%2BWkluWtuOeUn\% 2BihjOWLleioiOeVqy5wZGY\%3D\&icon=..pdf [URL inactive]

Ministry of Education. (2013). Top university project. Retrieved from www.edu.tw/ News_Plan_Content.aspx?n=D33B55D537402BAA\&sms $=954974 C 68391$ B710\&s =CBE2AF4E776CBCD5

Ministry of Education. (2016). MOE subsidy directions for the top university project. Retrieved from www.edu.law.moe.gov.tw/NewsContent.aspx?id=4279 [URL inactive]

National Central University. (2019, December 26). Recruitment announcement. www.most.gov.tw/bio/ch/detail?article_uid $=12544 \mathrm{df} 7-8 \mathrm{~d} 75-415 \mathrm{~b}-9 \mathrm{a} 2 \mathrm{a}-$ f2d3885453b4\&menu_id=ba3d22f3-96fd-4adf-a078-91a05b8f0166

National Taipei University of Technology. (2019, February 26). Recruitment announcement. Retrieved from www.ciie.org.tw/blank-34

Northcott, J. (2007). Towards an ethnography of the MBA classroom: A consideration of the role of interactive learning styles within the context of one MBA program. English for Specific Purposes, 20(1), 15-37. doi:10.1016/S0889-4906(99)00016-2

Pritasari, A., Reinaldo, H., \& Watson, C. W. (2019). English-medium instruction in Asian business schools: A case study. Journal of Multilingual and Multicultural Development, 40(1), 1-13.

Saks, A., \& Haccoun, R. (2019). Managing performance through training and development (8th ed.). Toronto, Canada: Nelson Education.

Taguchi, N., \& Naganuma, N. (2006). Transition from learning English to learning in English: Students' perceived adjustment difficulties in an English medium university in Japan. Asian EFL Journal, 8(4), 52-72.

Tsou, W. L. (2017). Interactional skills in engineering education. In W. L. Tsou \& S. M. Kao (Eds.), English as a medium of instruction in higher education: Implementations and classroom practices in Taiwan (pp. 79-182). Singapore: Springer.

Tsui, C. (2017). EMI teacher development programs in Taiwan. In W. L. Tsou \& S. M. Kao (Eds.), English as a medium of instruction in higher education (pp. 165-182). Singapore: Springer.

Wilkinson, R. (2011). If all business education were in English, would it matter? ITLInternational Journal of Applied Linguistics, 161(1), 111-123.

Wilkinson, R. (2012). English-medium instruction at a Dutch university: Challenges and pitfalls. In A. Doiz, D. Lasagabaster, \& J. M. Sierra (Eds.), English-medium instruction at universities: Global challenges (pp. 3-24). Bristol, UK: Multilingual Matters. 